\title{
Suppression of lipopolysaccharide-induced upregulation of toll-like receptor 4 by emodin in mouse proximal tubular epithelial cells
}

\author{
XIAO-LING ZHU ${ }^{1}$, YONG-JUN WANG ${ }^{1}$, YA-ZHEN YANG ${ }^{1}$, RU-CHUN YANG ${ }^{1}$, BIN ZHU $^{1}$, YING-HUA ZHANG ${ }^{1}$, \\ YI LIN ${ }^{1}$, YING LU ${ }^{1}$, XIAO-FENG LI ${ }^{2}$ and KEVIN T. O'BYRNE ${ }^{2}$ \\ ${ }^{1}$ Department of Nephrology, Hangzhou Hospital of Traditional Chinese Medicine (Hangzhou Guangxing Hospital), \\ Zhejiang Chinese Medical University, Hangzhou, Zhejiang 310007, P.R. China; ${ }^{2}$ Division of Reproduction and Endocrinology, \\ New Hunt's House, King's College London, Guy's Campus, London SE1 1UL, United Kingdom
}

Received January 26, 2012; Accepted April 16, 2012

DOI: $10.3892 / \mathrm{mmr} .2012 .960$

\begin{abstract}
The aim of this study was to investigate the effects of emodin, the major component of Rheum palmatum, on lipopolysaccharide (LPS)-induced toll-like receptor 4 (TLR4) expression in cultured mouse tubular epithelial cells (TECs). The TECs were obtained from mice and incubated with LPS and/or indicated concentrations of emodin for $24 \mathrm{~h}$. Cytokeratin, $\alpha$-SMA and vimentin were detected using immunohistochemistry. The TLR4 protein level was detected by flow cytometry. TNF $\alpha$ and IL- 6 protein levels were measured using an enzyme-linked immunosorbent assay (ELISA). mRNA expression of TLR4, TNF $\alpha$ and IL-6 was detected using a reverse-transcription polymerase chain reaction (RT-PCR). Results showed that a concentration of $10^{2} \mathrm{ng} / \mathrm{ml}$ LPS significantly upregulated TLR4 mRNA and protein levels. TNF $\alpha$ and IL-6 mRNA and protein levels were also increased. Emodin (at doses of 40,20 and $10 \mu \mathrm{M}$ ) was able to inhibit LPS-induced TLR4 protein synthesis in cultured TECs. However, TNF $\alpha$ and IL-6 protein expression was decreased in cells treated with emodin at concentrations of 40 and $20 \mu \mathrm{M}$. These results demonstrate that an elevated expression of inflammatory cytokines and TLR4 in cells stimulated with LPS, were simultaneously inhibited by emodin. Emodin is therefore able to inhibit the LPS-induced expression of TLR4 in order to downregulate TNF $\alpha$ and IL-6 synthesis in TECs, which may contribute to the protective effects of emodin in renal disease.
\end{abstract}

Correspondence to: Professor Xiao-Ling Zhu, Department of Nephrology, Hangzhou Hospital of Traditional Chinese Medicine (Hangzhou Guangxing Hospital), Zhejiang Chinese Medical University, Hangzhou, Zhejiang 310007, P.R. China

E-mail: zhuxiaolinghz@126.com

Key words: emodin, tubular epithelial cells, lipopolysaccharide, toll-like receptor 4 , tumor necrosis factor- $\alpha$, interleukin-6

\section{Introduction}

Infections can trigger disease activity in patients with immune complex glomerulonephritis (ICGN), including GN, $\operatorname{Ig}$ A nephropathy (IgAN), renal vasculitis, lupus nephritis and transplant rejection. However, tubulointerstitial damage has been demonstrated to be important in progressive renal disease (1). Glomerular injury is thought to trigger tubular cell activation, leading to tubulointerstitial inflammation and fibrosis. Activated tubule epithelial cells are considered to be critical in the pathogenesis of renal injury, due to their ability to secrete proinflammatory and profibrogenic substances (2). Therefore, renal functional damage correlates closely with tubulointerstitial damage in glomerulonephritis (1).

Toll-like receptors (TLRs) have been found to play a key role in the recognition of bacterial components during infection (3). Notably, TLR interactions with microbial components trigger the expression of proinflammatory cytokines as well as the functional maturation of antigen-presenting cells of the innate immune system (3-4). TLR activation may be a link between mechanical, toxic or ischemic tubular cell injury and the onset of an inflammatory 'innate' immune response in the pathogenesis of acute renal failure (5). Immune cells and intrinsic renal cells that respond to TLR activation may become activated by extracellular matrix molecules, which then promote the secretion of inflammatory cytokines and chemokines. This process in turn is followed by additional leukocyte recruitment to the kidney supporting sustained interstitial inflammation and interstitial fibrosis (6). Of the 13 known mammalian TLRs, TLR4 has received particular attention. TLR4 is involved in the signalling pathway of the lipopolysaccharide (LPS) receptor complex (7). Virulent uropathogenic strains (Escherichia coli) express P fimbriae, which bind to the glycolipid receptors of uroepithelial and kidney tubular cells, triggering TLR4 activation with subsequent recruitment of leukocytes and release of proinflammatory cytokines (8). Cytokines, tumor necrosis factor $\alpha(\mathrm{TNF} \alpha)$ and interleukin- 8 (IL-8) homologue are expressed in response to stimulation by LPS and a synthetic TLR4 agonist in cultured renal tubular epithelial cells (TECs) (9). Cells lacking the respective TLRs 
had a reduced response to this stimulation. The TLR4-mediated response to stimulation was dependent on nuclear factor $\kappa \mathrm{B}$ $(\mathrm{NF}-\kappa \mathrm{B})$ signalling, suggesting a role in the innate immune response to bacteria during ascending urinary tract infection. It has also been highlighted that although TLRs have specific ligands, co-operation may be required between these TLRs and other molecules to achieve a maximal response (9). Furthermore, activation of innate immunity through TLR4 in the donor kidney also contributes to the development of acute rejection after renal transplantation (10). Therefore, TLRs of renal cells are important in various kidney disorders and require further study.

Emodin (1,3,8-trihydroxy-6-methyl-anthraquinone) is a biologically active natural anthraquinone extracted from the roots and rhizomes of Rheum palmatum (Chinese name DaHuang) which is one of the four most well-known crude drugs in Traditional Chinese Medicine (TCM) history. It was described in Agriculture God's Canon of Materia Medica (Chinese name Shen Nong Ben Cao Jing) (11), in which the use of Rheum can be traced back to 270 B.C. At present, it is one of the most effective TCMs for infection and has now been officially listed in the Chinese Pharmacopoeia (12). Rheum has been confirmed to possess antimicrobial, antiviral, antiinflammatory, antifibrosis, antiulcerogenic, anti-cancer, immunosuppressive, vasorelaxant and chemopreventive effects (13-14). Furthermore, the anti-inflammatory properties of Rheum have been well-established in animal experiments and clinical studies (14). Emodin also has potential for the treatment of chronic renal failure (as an immunosuppressant and vasorelaxant). In a previous study, we found that compounds produced from the decoction of Centella Asiatica and Rheum repressed the proliferation and extracellular matrix production of rat kidney glomerular mesangial cells combined with a reduction in cyclin D1 and cyclin-dependent kinase 4 expression in rat (15-16). Although emodin was found to reduce monocyte/macrophage-chemoattractant protein-1 expression, inhibit TNF $\alpha$-induced NF- $\kappa \mathrm{B}$ and c-Jun N-terminal kinase, impair cytokine production (17) and even have an inhibitory effect against superoxide production (18), the detailed mechanisms underlying sensitization have not been established. It was recently reported that amelioration of pancreatic and pulmonary damage by emodin may partly contribute to the suppression of TLR4 expression (19), however, their relevance to TLR4 in TECs has not been investigated.

The present study investigated the anti-inflammatory mechanism of emodin by determining the effects on LPS-induced TLR4 expression in mice TECs cultures and aimed to determine whether emodin-ameliorated renal damage was mediated by its stimulation of intrinsic synthesis and release of $\mathrm{TNF} \alpha$ and IL-6 homologue in TECs.

\section{Materials and methods}

Antibodies and reagents. Emodin (molecular weight, 270.24; purity, 95\%) was purchased from the National Institute for the Control of Pharmaceutical and Biological Products (Beijing, China). Dulbecco's modified Eagle's medium (DMEM)-F12 culture medium and fetal calf serum (FCS) were purchased from Gibco (Carslbad, CA, USA). All other cell culture reagents were obtained from Sigma (St. Louis, MO, USA). Mouse anti-rat cytokeratin was purchased from ABR-Affinity BioReagents (ThermoScientific Pearce, Rockford, IL, USA). Mouse anti-rat $\alpha$-smooth actin ( $\alpha$-SMA) and vimentin were purchased from Wuhan Boster Biological Technology, Ltd. (Wuhan, China). LPS from E. coli (serotype, 0111:B4; cat. no., L-2630) was obtained from Sigma. The CytoTox $96^{\circledR}$ Nonradioactive Cytotoxicity Assay kit was obtained from Promega Corporation (Madison, WI, USA). TRIzol reagent was purchased from Invitrogen. Reagents for reverse transcription-polymerase chain reaction (RT-PCR) were purchased from Takara Biotechnology (Dalian, China). The anti-mouse TLR4 antibody was from BD Biosciences (Franklin Lakes, NJ, USA). Concentrations of TNF- $\alpha$ and IL- 6 were determined in culture supernatants using commercially available enzymelinked immunosorbent assay (ELISA) kits (R\&D Systems, Minneapolis, MN, USA).

Cell culture. Male BALB/c mice were purchased from the Shanghai Laboratory Animal Center Laboratory Co. Ltd. (SLAC, Shanghai, China). Primary proximal tubular cells (TECs) were obtained from 6-8 week old mice as previously described (20). Briefly, kidneys were bisected and the outer cortical tissue was separated from the mice. The tissue was then minced and digested in collagenase II at $37^{\circ} \mathrm{C}$ for $20 \mathrm{~min}$. The digest was then passed through various sieves (250, 160, 75 and $40 \mathrm{~nm})$. Cells trapped in the $40 \mathrm{~nm}$ sieve were collected by washing and centrifuging to obtain a pellet that was resuspended in DMEM-F12 supplemented with $2 \%$ FCS, $100 \mathrm{U} / \mathrm{ml}$ penicillin, $100 \mu \mathrm{g} / \mathrm{ml}$ streptomycin, $5 \mu \mathrm{g} / \mathrm{ml}$ insulin transferrin selenite (ITS), $10^{-12} \mathrm{M}$ triiodothyronine and $40 \mathrm{ng} / \mathrm{ml}$ hydrocortisone. The cell suspension was then seeded onto $1 \%$ gelatine-coated culture plates and incubated at $37^{\circ} \mathrm{C}$, at $5 \% \mathrm{CO}_{2}$. Cell phenotype was confirmed by immunohistochemistry.

Immunohistochemistry. For the measurement of the cytokeratin, $\alpha$-SMA and vimentin in cultured primary cells, immunohistochemistry was performed using mouse anti-rat monoclonal antibody cytokeratin (dilution, 1:200), mouse anti-rat monoclonal antibody $\alpha$-SMA and vimentin (dilution, 1:100), followed by incubation with biotinylated secondary antibody for $15 \mathrm{~min}$ and streptavidin-conjugated horseradish peroxidase (HRP) complex for a further $15 \mathrm{~min}$. After washing with phosphate-buffered saline (PBS), slides were incubated with substrate-chromogen solution (3,3'-diaminobenzidine, DAB) for $5 \mathrm{~min}$ and counterstained with Mayer's hematoxylin for 3 min. Images, including almost all of the cells, were captured using a light microscope.

Cytokine stimulation and emodin treatment of TECs. TECs were grown until confluent. Culture medium was changed to serum-free conditions $24 \mathrm{~h}$ prior to stimulation with LPS. Experiments were performed in triplicate using three consecutive wells of 6-well plates. Each experiment was repeated at least three times. The cells were incubated with LPS and/or the indicated concentrations $(10,20$ and $40 \mu \mathrm{M})$ of emodin for $24 \mathrm{~h}$. Cell viability (measured by exclusion of trypan blue) was $95-98 \%$ after treatment with the drug concentrations used in the inhibition studies. 
Table I. Sense and antisense primer sequences used in reverse-transcription polymerase chain reaction (RT-PCR).

\begin{tabular}{|c|c|c|c|c|c|}
\hline Gene & Primer pair (forward and reverse) & $\operatorname{Tm}\left({ }^{\circ} \mathrm{C}\right)$ & No. of cycles & Size (bp) & Genbank code \\
\hline TLR4 & $\begin{array}{l}\text { 5'-AAATGCCAGGATGATGCCTCCC-3' } \\
\text { 5'-AGTTTGAGAGGTGGTGTAAGCC-3' }\end{array}$ & 62 & 28 & 326 & XM-021297 \\
\hline $\mathrm{TNF} \alpha$ & $\begin{array}{l}\text { 5'-GCGAGGACAGCAAGGGACTA-3' } \\
\text { 5'-GTGTGGGTGAGGAGCACGTAG-3' }\end{array}$ & 60 & 30 & 621 & NM-013693 \\
\hline IL-6 & $\begin{array}{l}\text { 5'-ATTCCAGAAACCGCTATGAA-3' } \\
\text { 5'-CAC TAGGTTTGCCGAGTAGAT-3' }\end{array}$ & 62 & 30 & 653 & XM-031168 \\
\hline GAPDH & $\begin{array}{l}\text { 5'-ACCACAGTCCATGCCATCAC-3' } \\
\text { 5'-TCCACCACCCTGTTGCTGTA-3' }\end{array}$ & 60 & 28 & 453 & XM-033260 \\
\hline
\end{tabular}

TLR, toll-like receptor; TNF, tumor necrosis factor; IL, interleukin; Tm, melting temperature.

Cytotoxicity assay. The cytotoxicity assay was performed using a CytoTox 96 Nonradioactive Cytotoxicity Assay kit, according to the manufacturer's instructions. Briefly, after cells were incubated with LPS and emodin for $24 \mathrm{~h}$, medium samples were collected and spun at $4^{\circ} \mathrm{C}$ at $13,000 \mathrm{rpm}$ for $5 \mathrm{~min}$. To measure lactate dehydrogenase (LDH) activity, $50 \mu 1$ of each sample and $50 \mu 1$ of substrate were added in each well of 96-well plates. The assay plate was incubated for $30 \mathrm{~min}$ at room temperature. The LDH activity was recorded after adding stop solution by measuring the absorbance at $490 \mathrm{~nm}$. Background values were derived from the median of untreated TECs. Maximum LDH release values were derived from cell lysates by adding cell lysis solution to the monolayer. The percentage of cell deaths was determined using the formula: \%Cytotoxicity $=\left[\right.$ Experimental $\mathrm{LDH}$ release $\left(\mathrm{OD}_{490}\right)$ - Background values $\left.\left(\mathrm{OD}_{490}\right)\right] /\left[\mathrm{Maximum} \mathrm{LDH}\right.$ release $\left(\mathrm{OD}_{490}\right)$ + Background values $\left.\left(\mathrm{OD}_{490}\right)\right]$.

RT-PCR. Cells were treated with 10,20 and $40 \mu \mathrm{M}$ emodin for $24 \mathrm{~h}$ after stimulation with $10^{2} \mathrm{ng} / \mathrm{ml}$ LPS. Total RNA was extracted using TRIzol reagent. Total RNA $(1 \mu \mathrm{g})$ was reversetranscribed. PCR was performed using a One Step RNA PCR kit according to the manufacturer's instructions. The primer sequences used are shown in Table I. PCR amplifications were performed as follows: $5 \mathrm{~min}$ at $95^{\circ} \mathrm{C}$ followed by $28-30$ cycles consisting of $30 \mathrm{sec}$ at $95^{\circ} \mathrm{C}$, annealing (temperatures shown in Table I) for $30 \mathrm{sec}, 30 \mathrm{sec}$ at $72^{\circ} \mathrm{C}$, and an additional elongation step for $10 \mathrm{~min}$ at $72^{\circ} \mathrm{C}$. The PCR-amplified products were run on a $1.2 \%$ agarose gel and visualized by ethidium bromide staining. The expression intensities of optimized bands were quantified using a Luminescent Image Analyzer (Bio-Rad, Hercules, CA, USA).

Cell staining and flow cytometry. Cultured TECs were incubated with $25 \mathrm{mmol} / 1$ ethylenediaminetetraacetic acid (EDTA; pH 7.6) at $37^{\circ} \mathrm{C}$ for $10 \mathrm{~min}$. Detached cells were collected and washed in PBS. A total of $5 \times 10^{5}$ cells were incubated with $0.5 \mu \mathrm{g}$ of PE-conjugated anti-mouse TLR4 antibody, followed by incubation with goat anti-mouse IgG conjugated with fluorescein. The negative control was prepared by incubating with an isotype-matched control antibody (IgG2a). The incubation was performed in $50 \mu \mathrm{l}$ of PBS
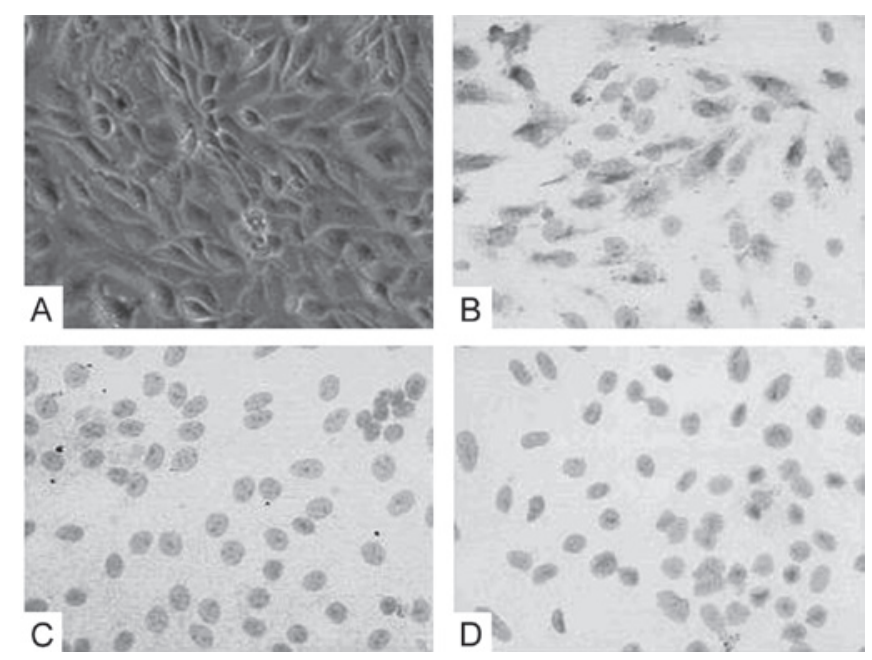

Figure 1. (A) Primary TEC cultures visualized by light microscopy. (B) Positive staining for cytokeratin in cultured TECs detected by immunohistochemistry. (C) Negative staining for $\alpha$-SMA antibody in cultured TECs. (D) Negative staining for vimentin antibody in cultured TECs. Magnification, $\mathrm{x} 400$. TEC, tubular epithelial cell; $\alpha$-SMA, $\alpha$-smooth actin.

at $4^{\circ} \mathrm{C}$ for $30 \mathrm{~min}$, followed by washing three times in $2 \mathrm{ml}$ of PBS with $1 \%$ bovine serum albumin. The cells were then fixed in $400 \mu \mathrm{l}$ of $2 \%$ paraformaldehyde in PBS and analyzed by FACScan flow cytometry (Beckman-Coulter, Miami, FL, USA).

ELISA. To quantify the level of TNFa and IL-6 protein expression under the different experimental conditions, the total TNF $\alpha$ and IL- 6 protein in the culture supernatant was measured using a commercial sandwich ELISA kit for TNF $\alpha$ and IL- 6 according to the manufacturer's instructions. Samples were assayed in duplicate.

Statistical analysis. Experiments were performed in triplicate and repeated three times. The data were shown as the mean \pm standard deviation (SD). Data were analyzed using SPSS 10.0 software (SPSS Inc., USA). Statistical significance was assessed by ANOVA and the unpaired t-test. $\mathrm{P}<0.05$ was considered to indicate a statistically significant difference. 
A

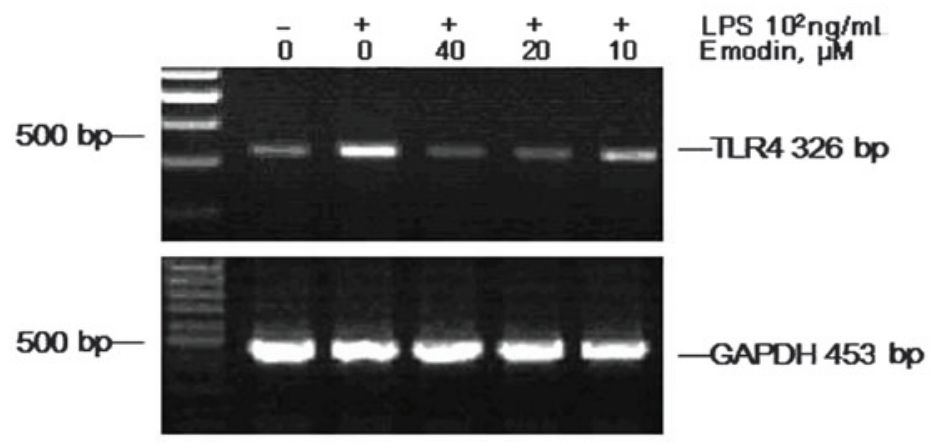

B
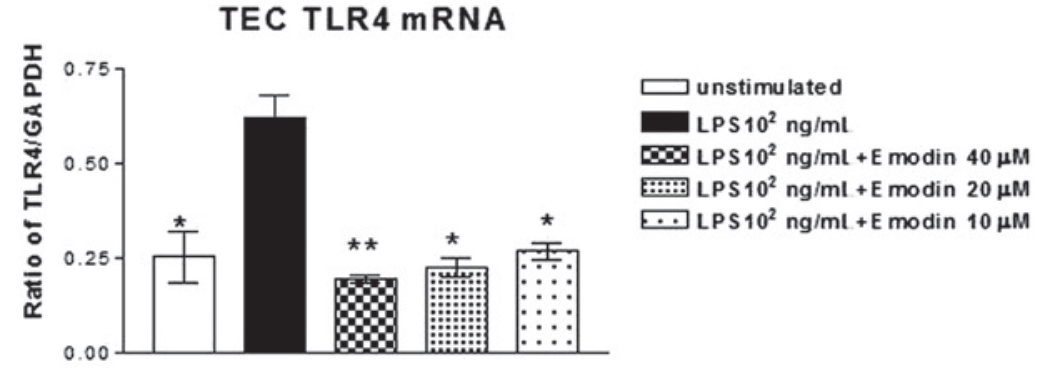

C
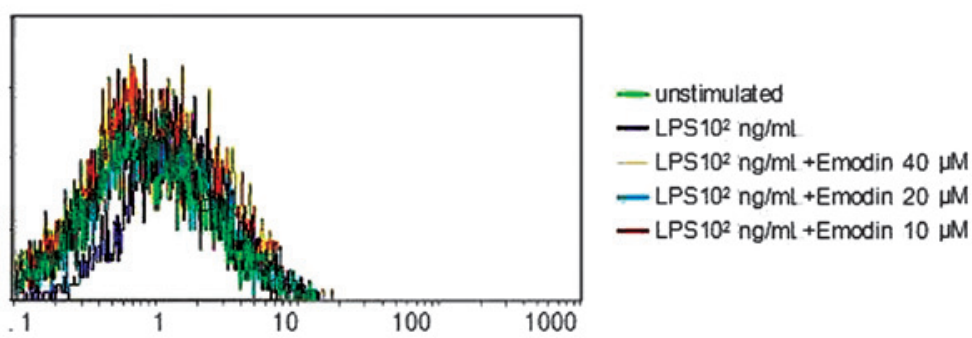

- LPS $10^{2} \mathrm{ng} / \mathrm{ml}+$ Emodin $10 \mu \mathrm{M}$

D

Flow Cy tom etry for TEC TLR4
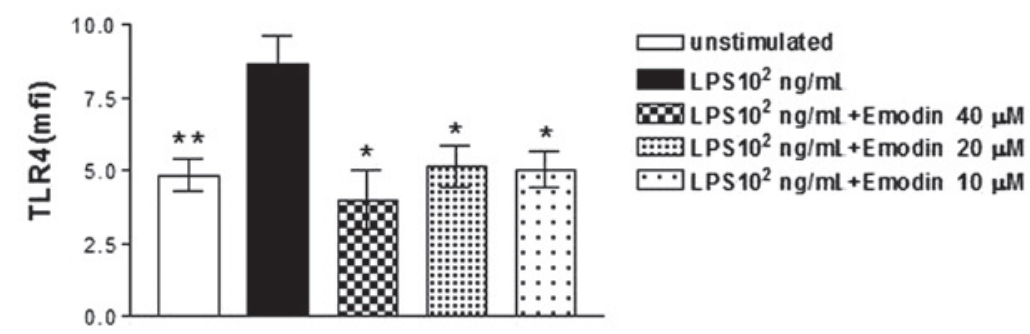

Figure 2. Effects of emodin on LPS-stimulated TLR4 mRNA and protein production in TECs. TECs incubated with LPS $10^{2} \mathrm{ng} / \mathrm{ml}$ in the presence of emodin for $24 \mathrm{~h}$ and TLR4 mRNA and protein were evaluated by RT-PCR and flow cytometry respectively. (A) Emodin inhibited the expression of TLR4 mRNA at doses of 40,20 and $10 \mu \mathrm{M}$, respectively. (B) The results normalized by expressing the number of transcript copies as a ratio to GAPDH. Data are the mean \pm SD. The inhibitory effect of emodin demonstrates a dose-dependent manner. (C) Effect of emodin on TLR4 expression in TECs. Flow cytometry of the TLR4 surface protein was performed in TECs from the control and treated cells with emodin at doses of 40, 20 and $10 \mu \mathrm{M}$ for $24 \mathrm{~h}$, respectively. (D) The abovementioned results were summarized. ${ }^{*} \mathrm{P}<0.05$ and ${ }^{* * *} \mathrm{P}<0.01$ versus unstimulated TECs. LPS, lipopolysaccharide; TLR, toll-like receptor; TEC, tubular epithelial cells; RT-PCR, real time-polymerase chain reaction; SD, standard deviation.

\section{Results}

The primary TEC cells were successfully identified as renal TECs by light microscopy (Fig. 1A). Cell phenotype was confirmed by positive staining for cytokeratin antibody (Fig. 1B) and negative staining for $\alpha$-SMA antibody and vimentin antibody (Fig. $1 \mathrm{C}$ and $\mathrm{D}$ ).

Inhibitory effects of emodin on TLR4 $m R N A$ and protein expression by LPS-stimulated TECs. In accordance with previous studies, we found that TLR4 synthesis by TECs was upregulated following $24 \mathrm{~h}$ stimulation with LPS (7). TLR4 expression was increased more significantly at a dose of $10^{2} \mathrm{ng} / \mathrm{ml}$ than $10 \mathrm{ng} / \mathrm{ml}$ and $10^{3} \mathrm{ng} / \mathrm{ml}$ (data not shown). Therefore, we adopted the concentration of $10^{2} \mathrm{ng} / \mathrm{ml}$ LPS for our study.

The concentrations of emodin used in this study were based on previous experiments (16-17), and it was verified that these doses were not cytotoxic in cultured TECs by LDH release assay (Figs. 2-4). To determine the effects of emodin on TLR4 mRNA expression, TECs stimulated with or without LPS $\left(10^{2} \mathrm{ng} / \mathrm{ml}\right)$ were incubated with emodin at concentrations of 10, 20 and $40 \mu \mathrm{M}$. Emodin $(\mathrm{P}<0.05)$ was able to inhibit LPS-stimulated TLR4 protein synthesis in cultured TECs, but 
A

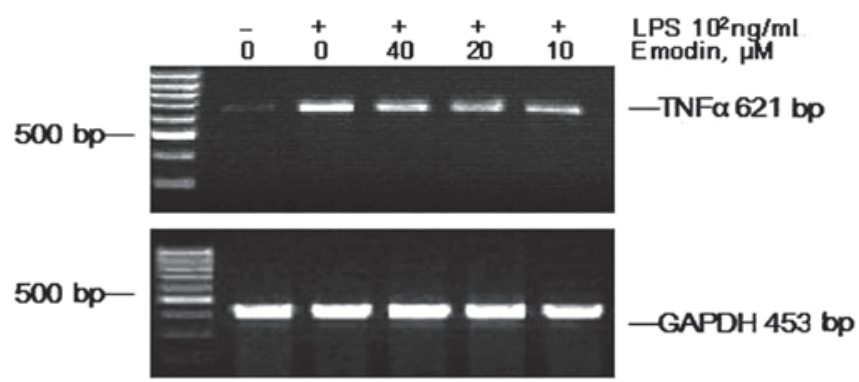

B

TEC TNF $\alpha$ mRNA
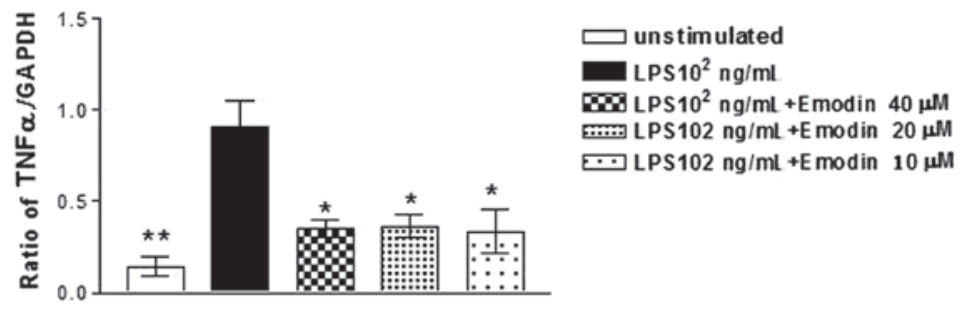

C

ELISA for TEC medium TNF $\alpha$
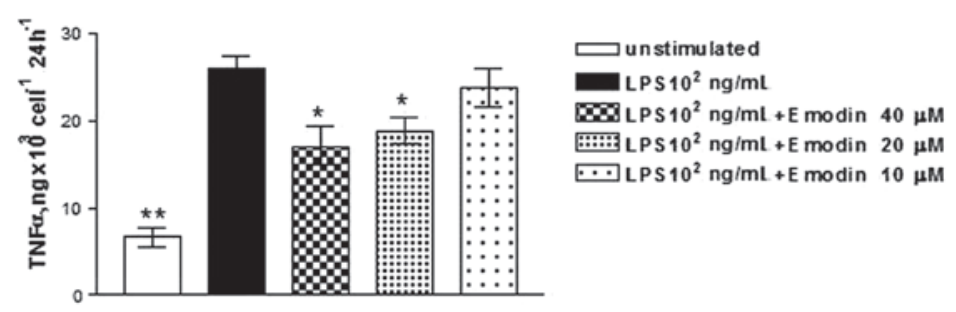

Figure 3. Effects of emodin on LPS-stimulated TNF $\alpha$ mRNA and protein secretion in TECs. The TECs incubated with LPS $10^{2} \mathrm{ng} / \mathrm{ml}$ in the presence of emodin for $24 \mathrm{~h}$ and TNF $\alpha$ mRNA and protein were evaluated by RT-PCR and ELISA. (A) Emodin inhibited the expression of TNF $\alpha$ mRA at doses of 40, 20 and $10 \mu \mathrm{M}$. (B) The results normalized by expressing the number of transcript copies as a ratio to GAPDH. Data are the mean \pm SD. (C) Emodin doses used were 40, 20 and $10 \mu \mathrm{M}$. The expression of TNF $\alpha$ protein secretion was analyzed by ELISA. The inhibitory effect of emodin demonstrates a dose-dependent manner. ${ }^{\mathrm{P}}<0.05$ and ${ }^{* *} \mathrm{P}<0.01$ versus unstimulated TECs. LPS, lipopolysaccharide; TLR, toll-like receptor; TEC, tubular epithelial cells; RT-PCR, real timepolymerase chain reaction; ELISA, enzyme-linked immunosorbent assay; SD, standard deviation.

with distinct differences in action intensity (Fig. 2A and B). Emodin at a dose of $40 \mu \mathrm{M}$ demonstrated maximum suppression of TLR4 mRNA expression in LPS-stimulated cells. Similar to its effect on TLR4 protein expression, emodin inhibited the LPS-upregulated synthesis of the TLR4 surface protein in a dose-dependent manner (Fig. 2C and D).

Inhibitory effects of emodin on TNF $\alpha$ and IL-6 mRNA and the protein expression by LPS-stimulated TECs. To study the effects of LPS on the expression of TNF $\alpha$ and IL-6, we evaluated mRNA and protein expression using RT-PCR and ELISA in LPS-stimulated TECs. TNF $\alpha$ and IL-6 mRNA were hardly detected in unstimulated TECs. After incubation with LPS $\left(10^{2} \mathrm{ng} / \mathrm{ml}\right)$ for $24 \mathrm{~h}$, TNF $\alpha$ and IL- 6 mRNA expression was significantly increased (data not shown). TNF $\alpha$ and IL-6 protein secretions in cell culture medium were increased 2- and 4-fold, respectively, as demonstrated by using the ELISA method. Corresponding to TNF $\alpha$ and IL-6 mRNA expression, synthesis of the TNF $\alpha$ and IL- 6 protein was also increased (data not shown).

To examine the effects of emodin on TNF $\alpha$ and IL-6 mRNA expression induced by LPS in TECs, the cells were stimulated with or without LPS $\left(10^{2} \mathrm{ng} / \mathrm{ml}\right)$ and incubated with emodin at different doses for $24 \mathrm{~h}$. TNF $\alpha$ and IL-6
mRNA expression was measured by RT-PCR. Emodin inhibited LPS-induced TNF $\alpha$ and IL-6 mRNA expression (Figs. 3A and 4A). At a dose of $10 \mu \mathrm{M}$, the inhibitory effects of emodin on TNF $\alpha$ and IL- 6 protein secretion were significant, but were lower than the concentrations (Figs. 3B and 4B) of 20 and $40 \mu \mathrm{M}$ compared with LPS-stimulated cells ( $\mathrm{P}>0.05)$. Emodin at concentrations of 40 and $20 \mu \mathrm{M}$ had an effect on TNF $\alpha$ and IL-6 protein secretion. Therefore, emodin inhibited TNF $\alpha$ and IL-6 secretion in a dose-dependent manner.

\section{Discussion}

Our results demonstrate for the first time and to the best of our knowledge that emodin inhibited LPS-induced TLR4 expression in cultured TECs, as well as partly blocked LPS-stimulated TNF $\alpha$ and IL-6 upregulation. Certain data from our previous study demonstrated that compounds produced from decoction of Rheum repressed the proliferation and extracellular matrix production of glomerular mesangial cells via a decrease in cyclin D1 and cyclin-dependent kinase 4 levels in rats (15-16). These studies suggest that emodin is able to inhibit the process of glomerulosclerosis. In the present study, the effect of emodin in the TECs is likely to be complex and interrelated to downregulate TLR4, TNF $\alpha$ and IL-6. It is considered that 
A

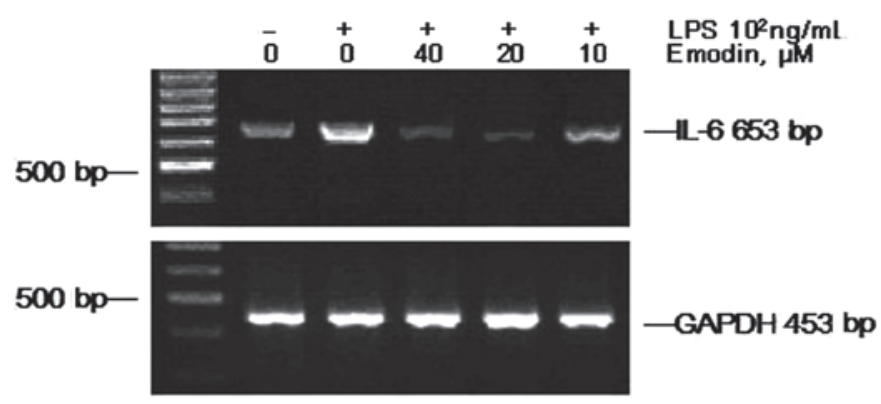

B

TEC IL-6 mRNA

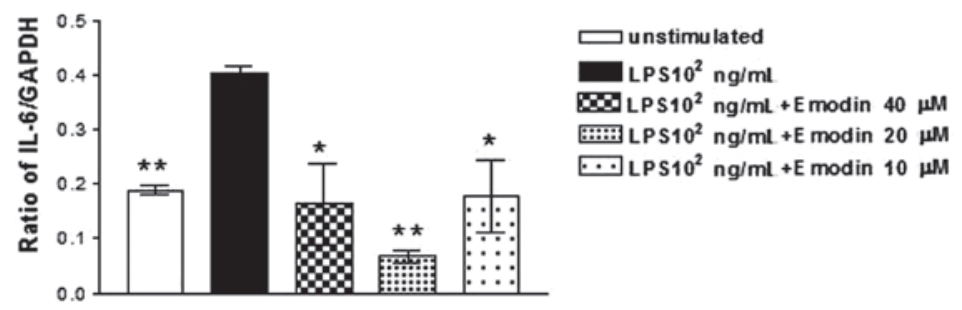

C

\section{ELISA for TEC medium IL-6}

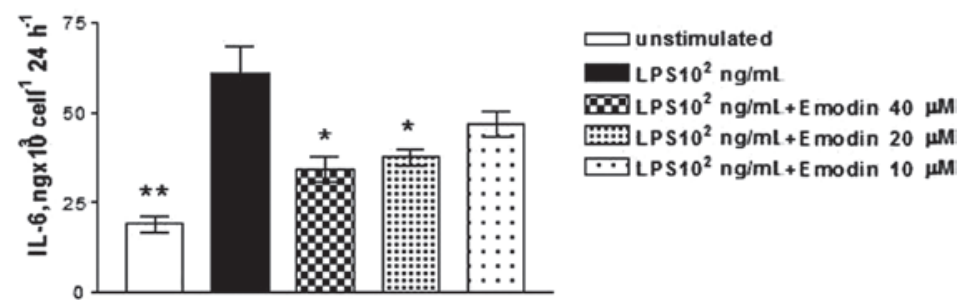

Figure 4. Effects of emodin on LPS-stimulated IL- 6 mRNA and protein secretion in TECs. The TECs incubated with LPS $10^{2} \mathrm{ng} / \mathrm{ml}$ in the presence of emodin for $24 \mathrm{~h}$ and IL- 6 mRNA and protein were evaluated by RT-PCR and ELISA. (A) Emodin inhibited the expression of IL- 6 mRNA at doses of 40,20 and $10 \mu \mathrm{M}$. (B) The results normalized by expressing the number of transcript copies as a ratio to GAPDH. Data are the mean \pm SD. (C) Emodin doses used were 40, 20 and $10 \mu \mathrm{M}$. The expression of IL-6 protein secretion was analyzed by ELISA. The inhibitory effect of emodin demonstrates a dose-dependent manner. ${ }^{*} \mathrm{P}<0.05$ and ${ }^{* *} \mathrm{P}<0.01$ versus unstimulated TECs. LPS, lipopolysaccharide; IL-interleukin; TEC, tubular epithelial cells; RT-PCR, real time-polymerase chain reaction; ELISA, enzyme-linked immunosorbent assay; SD, standard deviation

an increased understanding of this process is likely to lead to therapies that are able to effectively prevent or reverse inflammation in TECs.

LPS is one of the most studied immunostimulatory components of bacteria that can induce systemic inflammation when excessive signalling occurs (21) Thus, it has been widely used as a stimulating factor in research on TLR4 in infective diseases. We investigated the effects of emodin on cultured TECs. The results are consistent with previous findings (9) that TLR4 mRNA and protein expression were upregulated by LPS, which also paralleled the severity of increased TNF $\alpha$ and IL-6 mRNA and protein expression in cultured mouse TECs, supporting the hypothesis that LPS is the key molecule in the overexpression of TLR4 and cytokines.

Previous reports investigating significant differences between wild-type and TLR4 knockout mice have demonstrated that TLR4 is significant in renal pathophysiological conditions (22). By performing renal cross-transplantation between wild-type and TLR4 knockout mice, Cunningham et al revealed that kidneys of TLR4 knockout mice in wild-type hosts remained susceptible to endotoxin-induced renal failure (23). Furthermore, Tamm-Horsfall glycoprotein-driven cytokine production was evident in wild-type mice compared with TLR4-knockout mice. The generation of Tamm-Horsfall glycoprotein-specific antibodies was consistently detectable in urinary tract inflammation and was completely blunted in TLR4-knockout mice (24). TECs from TLR4-knockout mice failed to respond to LPS and cytokines released by them were decreased (2). These data suggest that the intrarenal expression of TLR4 is important for the development of renal injury. In the present study, we demonstrated that the expression of TLR4 was significantly upregulated $24 \mathrm{~h}$ after stimulation with $10^{2} \mathrm{ng} / \mathrm{ml}$ LPS. The detection of TLR4 on TECs also revealed a potential site for inflammation initiation based on TLR4. Banas et al detected intense TLR4 immunoreactivity in mouse models of membranoproliferative glomerulonephritis (25). Zhang et al also provided compelling evidence that the activation of TLR4 present on renal parenchymal cells triggers an innate immune response that mediates cisplatininduced acute renal failure (26). Thus, TLR4 is critical in the progression of immunoreactivity. Therefore, the inhibition of TLR4 overexpression has become particularly significant for the management of renal inflammatory disease. Emodin is the main effective composition in certain Chinese herbs. Previous studies have revealed that the laboratory signs of rat renal lesions were significantly ameliorated by emodin, as demonstrated by 
decreased blood creatinine, urea and 24-h urine protein in the renal failure models after administration with emodin $(12,27)$. Furthermore, in vitro studies have also revealed that emodin is able to inhibit proliferation of glomerular mesangial cells and TECs by decreasing the expression of c-Myc mRNA, increasing the p27 level, delaying the progression from $\mathrm{G} 1$ to $\mathrm{S}$ phase and promoting apoptosis of renal fibroblasts, thus intervening in progressive renal disease $(12,28-29)$. Previous studies of autoimmunity have demonstrated that emodin significantly suppressed the expression of pancreatic and pulmonary TLR4, at the level of mRNA transcription and protein synthesis (17). The authors speculated that amelioration of pancreatic and pulmonary damage by emodin may contribute, at least in part, to the suppression of TLR4 expression. This finding suggested that emodin is a potential drug target for TLR4 (17). However, no studies have yet described emodin's ability to suppress LPS-induced TLR4 expression in intrinsic renal cells. In the present study, it was observed that emodin effectively reversed LPS upregulated TLR4 mRNA and protein expression at concentrations of 10,20 and $40 \mu \mathrm{M}$ in cultured mouse TECs. When compared with LPS-stimulated group, co-culture with emodin significantly reversed LPS-induced expression of TLR4 in cultured mice TECs, and the effect was dose-dependent. The results also demonstrated an absence of $\mathrm{LDH}$ release and the appearance of of well-maintained cell viability and unaltered house keeping gene expression, indicating that reduced mRNA and protein expression are unlikely to indicate toxicity of the reagents. The results from the present study raise the possibility that emodin has good prospects as a treatment for renal disease by suppression of TLR4.

While we have demonstrated that the LPS-induced expression of TLR4 was suppressed by emodin in the present study, the ligation of TLR4-induced production of pro-inflammatory cytokines cannot be ignored. Consequently, we examined the inhibitory effects of emodin on the overexpression of TNF $\alpha$ and IL- 6 in TECs. Emodin inhibited TNF $\alpha$ and IL- 6 activity in a dose-dependent manner. In the presence of 20 and $40 \mu \mathrm{M}$ emodin, TNF $\alpha$ and IL-6 mRNA and protein expression were markedly decreased compared with the slight inhibition of TNF $\alpha$ and IL- 6 protein in the presence of $10 \mu \mathrm{M}$ emodin. Thus, TECs respond diffusely to local infection, with the release of multiple cytokines, chemokines and other factors that are considered to orchestrate the cellular constituents of the innate immune response (30). Moreover, the expression of TLR4 may be involved in regulating immune cells to synthesise cytokines (31). Other in vivo studies have also suggested that cytokines released by mesangial cells may contribute to the pathology and disease progression of IgA nephropathy (IgAN) (32). Findings of a previous study showed that the main proinflammatory cytokines, $\mathrm{TNF} \alpha$ and IL-6, were also significantly upregulated in a rat model of diabetic nephropathy (33). Therefore, it was suggested that TLR4 is important for the inflammatory response during initiation and progression of nephropathy. The results from the present study demonstrate a compelling contribution of emodin in renal inflammatory disease.

The present study has provided evidence that emodin not only suppresses LPS-induced TLR4 overexpression, but also inhibits TNF $\alpha$ and IL-6 activity. Furthermore, the elevated levels of inflammatory cytokines, as well as an increased expression of TLR4, were simultaneously inhibited by emodin. Considering that the TLR4 signalling pathway may stimulate the release of TNF $\alpha$ and IL-6 (34-35), we suggest that the decrease in TNF $\alpha$ and IL- 6 levels by administration of emodin may contribute to the suppression of TLR4, thus elucidating the mechanism of TLR4 suppression and ICGN alleviation by treatment with emodin.

\section{Acknowledgements}

This study was supported by grants from the Project of National Natural Science Foundation of China (No. 81173426), the Project of Hangzhou Medical Scientific Technology (No. 2005Z007), the Project of the Hangzhou Science and Technology Bureau Foundation (No. 20080333Q17) and the Project of Zhejiang Provincial Health Department Financed Project (No.2008A135).

\section{References}

1. Theilig F, Kriz W, Jerichow T, et al: Abrogation of protein uptake through megalin-deficient proximal tubules does not safeguard against tubulointerstitial injury. J Am Soc Nephrol 18: 1824-1834. 2007.

2. Chassin C, Goujon JM, Darche S, et al: Renal collecting duct epithelial cells react to pyelonephritis-associated Escherichia coli by activating distinct TLR4-dependent and -independent inflammatory pathways. J Immunol 177: 4773-4784, 2006.

3. Akira S, Uematsu S and Takeuchi O: Pathogen recognition and innate immunity. Cell 124: 783-801, 2006.

4. Lee HK and Iwasaki A: Innate control of adaptive immunity: dendritic cells and beyond. Semin Immunol 19: 48-55, 2007.

5. Zager RA, Johnson AC, Lund S and Randolph-Habecker J: Toll-like receptor (TLR4) shedding and depletion: acute proximal tubular cell responses to hypoxic and toxic injury. Am J Physiol Renal Physiol 292: 304-312, 2007.

6. Wynn TA: Cellular and molecular mechanisms of fibrosis. J Pathol 214: 199-210, 2008.

7. Poltorak A, He X, Smirnova I, et al: Defective LPS signaling in $\mathrm{C} 3 \mathrm{H} / \mathrm{HeJ}$ and $\mathrm{C} 57 \mathrm{BL} / 10 \mathrm{ScCr}$ mice: mutations in Tlr4 gene. Science 282: 2085-2088, 1998.

8. Scherberich JE and Hartinger A: Impact of Toll-like receptor signalling on urinary tract infection. Int J Antimicrob Agents 31: 9-14, 2008

9. Chowdhury P, Sacks SH and Sheerin NS: Toll-like receptors TLR2 and TLR4 initiate the innate immune response of the renal tubular epithelium to bacterial products. Clin Exp Immunol 145: 346-356, 2006

10. Palmer SM, Burch LH, Mir S, et al: Donor polymorphisms in Toll-like receptor-4 influence the development of rejection after renal transplantation. Clin Transplant 20: 30-36, 2006.

11. Li S, Dong X, Wu H, Zhang L and Zhang D: Progress in studies on pharmacological effect of rhubarb and its active components. Medical Recapitulate 1: 76-78, 2005.

12. China Pharmacopoeia Committee, Pharmacopoeia of the People's Republic of China (First Division of 2000 ed.) China Chemical Industry Press, Beijing, p.18, 1999.

13. Kwak HJ, Park MJ, Park CM, et al: Emodin inhibits vascular endothelial growth factor-A-induced angiogenesis by blocking receptor-2 (KDR/Flk-1) phosphorylation. Int J Cancer 118: 2711-2720, 2006.

14. Wang R, Wan Q, Zhang Y, et al: Emodin suppresses interleukinlbeta induced mesangial cells proliferation and extracellular matrix production via inhibiting P38 MAPK. Life Sci 80: 2481-2488,2007.

15. Zhu XL, Wang J, Zhou DW, et al: Experimental studies on prevention and treatment of glomerulosclerosis with Centella Asiatica compound and its mechanism. Chin J Nephrol 17: 199-200, 2001.

16. Zhu XL, Wang YJ, Cheng XX, Tong ML, Chen HY and Zhang MS: Effects of niaodujing II on cyclin D1, CDK4 in cultured glomerular mesangial cells in human. Chin J Integr Tradit West Nephrol 6: 316-318, 2004. 
17. Kitano A, Saika S, Yamanaka O, et al: Emodin suppression of ocular surface inflammatory reaction. Invest Ophthalmol Vis Sci 48: 5013-5022, 2007.

18. Chen RF, Shen YC, Huang HS, et al: Evaluation of the anti-inflammatory and cytotoxic effects of anthraquinones and anthracenes derivatives in human leucocytes. J Pharm Pharmacol 56: 915-919, 2004.

19. Li Z, Xia X, Zhang S, Zhang A, Bo W and Zhou R: Up-regulation of Toll-like receptor 4 was suppressed by emodin and baicalin in the setting of acute pancreatitis. Biomed Pharmacother 63: $120-128,2009$

20. Springall T, Sheerin NS, Abe K, Holers VM, Wan H and Sacks SH: Epithelial secretion of C3 promotes colonization of the upper urinary tract by Escherichia coli. Nat Med 7: 801-806, 2001.

21. Beutler B and Rietschel ET: Innate immune sensing and its roots: the story of endotoxin. Nat Rev Immunol 3: 169-176, 2003.

22. El-Achkar TM and Dagher PC: Renal Toll-like receptors: recent advances and implications for disease. Nat Clin Pract Nephrol 2: 568-581, 2006

23. Cunningham PN, Wang Y, Guo R, He G and Quigg RJ: Role of Toll-like receptor 4 in endotoxin-induced acute renal failure. J Immunol 172: 2629-2635, 2004.

24. Säemann MD, Weichhart T, Zeyda M, et al: Tamm-Horsfall glycoprotein links innate immune cell activation with adaptive immunity via a Toll-like receptor-4-dependent mechanism. J Clin Invest 115: 468-475, 2005.

25. Banas MC, Banas B, Hudkins KL, et al: TLR4 links podocytes with the innate immune system to mediate glomerular injury. J Am Soc Nephrol 19: 704-713, 2008.

26. Zhang B, Ramesh G, Uematsu S, Akira S and Reeves WB: TLR4 signaling mediates inflammation and tissue injury in nephrotoxicity. J Am Soc Nephrol 19: 923-932, 2008.
27. Wang J, Huang H, Liu P, et al: Inhibition of phosphorylation of p38 MAPK involved in the protection of nephropathy by emodin in diabetic rats. Eur J Pharmacol 553: 297-303, 2006.

28. Liu G, Ye R and Tan Z: Effect of emodin on fibroblasts in lupus nephritis. Zhongguo Zhong Xi Yi Jie He Za Zhi 20: 196-198, 2000.

29. Mei XB, Yuan WJ, Zhan FL, Wu H, Zhang XY and Cui RL: Role of cyclin kinase inhibitor p27 in inhibition of emodin on mesangial cell proliferation induced by tumor necrosis factoralpha. Zhong Xi Yi Jie He Xue Bao 2: 120-122, 2004.

30. Yeboah MM, Xue X, Duan B, Ochani M, Tracey KJ, Susin M and Metz CN: Cholinergic agonists attenuate renal ischemiareperfusion injury in rats. Kidney Int 74: 62-69, 2008

31. Ando M, Shibuya A, Tsuchiya K, Akiba T and Nitta K: Reduced expression of Toll-like receptor 4 contributes to impaired cytokine response of monocytes in uremic patients. Kidney Int 70: 358-362, 2006.

32. Leung JC, Tang SC, Chan LY, Chan WL and Lai KN: Synthesis of TNF-alpha by mesangial cells cultured with polymeric anionic IgA - role of MAPK and NF-kappaB. Nephrol Dial Transplant 23: 72-81, 2008.

33. Navarro JF, Milena FJ, Mora C, León C and García J: Renal proinflammatory cytokine gene expression in diabetic nephropathy: effect of angiotensin-converting enzyme inhibition and pentoxifylline administration. Am J Nephrol 26: 562-570, 2006.

34. Johnson GB, Brunn GJ and Platt JL: Cutting edge: an endogenous pathway to systemic inflammatory response syndrome (SIRS)-like reactions through Toll-like receptor-4. J Immunol 172: 20-24, 2004.

35. Ogawa Y, Tasaka S, Yamada W, Saito F, Hasegawa N, Miyasho T and Ishizaka A: Role of toll-like receptor 4 in hyperoxia-induced lung inflammation in mice. Inflamm Res 56: 334-338, 2007. 